\title{
The impact of thoracic endovascular aortic repair on long-term survival in type B aortic dissection
}

\author{
Christos D. Karkos ${ }^{1}$, Ignacio Hernandez-Lahoz ${ }^{2}$, Nikolaos Asaloumidis ${ }^{1}$, Konstantinos O. Papazoglou ${ }^{1}$ \\ ${ }^{1}$ Vascular Unit, $5^{\text {th }}$ Department of Surgery, Medical School, Aristotle University of Thessaloniki, Thessaloniki, Greece; ${ }^{2}$ Vascular Surgery Unit, \\ Montecelo Hospital, Pontevedra, Spain \\ Correspondence to: Christos D. Karkos, MD, FRCS, PhD, EBIR, FEBVS. Vascular Unit, $5^{\text {th }}$ Department of Surgery, Medical School, Aristotle \\ University of Thessaloniki, Hippocrateio Hospital, Konstantinoupoleos 49, Thessaloniki 546 42, Greece. Email: ckarkos@hotmail.com. \\ Provenance: This is a Guest Editorial commissioned by Section Editor Busheng Zhang, PhD, MD (Department of Cardiac Surgery, Shanghai Chest \\ Hospital, Shanghai Jiaotong University, Shanghai, China). \\ Comment on: Lou X, Chen EP, Duwayri YM, et al. The Impact of Thoracic Endovascular Aortic Repair on Long-Term Survival in Type B Aortic \\ Dissection. Ann Thorac Surg 2017. [Epub ahead of print].
}

Submitted Oct 09, 2017. Accepted for publication Oct 11, 2017.

doi: $10.21037 /$ atm.2017.10.13

View this article at: http://dx.doi.org/10.21037/atm.2017.10.13

Type B aortic dissection (AD) is a potentially fatal disease with poor long-term outcome. In the modern endovascular era, thoracic endovascular aortic repair (TEVAR) is considered the treatment of choice in complicated acute type $\mathrm{B} \mathrm{AD}$, whereas uncomplicated acute type $\mathrm{B} \mathrm{AD}$ has traditionally been managed nonoperatively (1). Approximately $30 \%$ of type B AD patients present with ischemia or rupture and represent a subgroup with significant in-hospital mortality (1). Indications for endovascular intervention include persistent or recurrent pain, uncontrolled hypertension despite full medication, early aortic expansion, malperfusion, and signs of rupture (hemothorax, increasing periaortic and mediastinal hematoma) (1). Those with an uncomplicated acute type $\mathrm{B} A \mathrm{D}$ are treated with optimal medical therapy and lifelong periodical imaging surveillance. The latter is crucial to detect significant late aneurysmal dilatation, which then needs to be addressed by endovascular procedures or open surgery. Given the disappointing long-term results with optimal medical therapy and the emerging data regarding the efficacy of TEVAR in remodeling the dissected aorta, many investigators now suggest a more aggressive strategy of TEVAR at the initial hospitalization for the treatment of patients with acute uncomplicated type B AD. However, quality evidence is lacking.

A recent paper by Lou et al. provides us with important "natural history" data that add to the growing body of evidence demonstrating poor long-term outcomes in medically-treated patients with uncomplicated type B AD (2). The authors, who come from the Divisions of Cardiothoracic Surgery and Vascular and Endovascular Therapy, Emory University School of Medicine, Atlanta, Georgia, reviewed 398 patients with acute type B AD between 2000 and 2016. At index hospitalization, complicated patients underwent TEVAR $(n=80)$ and uncomplicated patients received optimal medical therapy $(\mathrm{n}=318)$. Uncomplicated patients were divided into three subgroups based on final treatment: (I) TEVAR (in the chronic phase, $n=87$ ); (II) open aortic replacement $(\mathrm{n}=59)$; and (III) optimal medical therapy $(\mathrm{n}=172)$. In the uncomplicated group, 146 patients (45.9\%) patients failed optimal medical therapy, and underwent open $(n=59)$ or endovascular $(\mathrm{n}=87)$ repair in the chronic phase. Despite a higher mortality risk at presentation, there was a trend toward improved long-term survival among complicated acute type B AD patients (complicated $84.1 \%$ vs. uncomplicated $58.9 \%, \mathrm{P}=0.17$ ). The authors' conclusions were that treatment of uncomplicated acute type $\mathrm{B} \mathrm{AD}$ with optimal medical therapy results in a high incidence of surgical intervention and poor long-term survival. Therefore, TEVAR during the index hospitalization may confer a survival advantage and serve as optimal therapy for both complicated and uncomplicated acute type $\mathrm{B} \mathrm{AD}$ patients. 
A striking finding in the study was that almost half the patients with an initially uncomplicated type $\mathrm{B} A \mathrm{AD}$ eventually ended up needing an operation, open or endovascular. This is an important observation since TEVAR appears to be less effective in the chronic phase than it is when performed in the acute phase. The likely explanation for this discrepancy is that the dissection flap has become fibrotic and rigid, and, therefore, it is more difficult for the stent-graft to move the thick septum. This is turn, and it may lead to incomplete false lumen thrombosis and failure to stabilize or reduce the aneurysm size (2). In contrast, TEVAR is highly effective in remodeling the aorta in the acute phase and will reduce the incidence of late false lumen aneurysm formation and aortic-related mortality. On the other hand, the main disadvantages of early "prophylactic" TEVAR are the high endograft costs, and the procedural risks of retrograde type A dissection, stroke, and spinal cord ischemia in some of the patients who may never require intervention. To minimize these risks, certain authors advocate delaying treatment for a few weeks and intervening in the subacute phase, i.e., between 15 and 90 days, when the dissection flap matures and stabilizes (3-5).

Perhaps, the correct question here is not whether to perform a "prophylactic" TEVAR in all acute uncomplicated type B AD patients, but which patients will benefit from such therapy. A recent study from Boston documented that nearly $40 \%$ of patients who present with an uncomplicated type $\mathrm{B} \mathrm{AD}$ will ultimately require an aortic intervention (6). Predictors of late aortic intervention included entry tear $>10 \mathrm{~mm}$, total aortic diameter $>40 \mathrm{~mm}$ at time of presentation, false lumen diameter $>20 \mathrm{~mm}$, and increase in total aortic diameter $>5 \mathrm{~mm}$ between serial imaging studies. Complete thrombosis of the false lumen was protective against late operative intervention. Therefore, it is likely that these readily available anatomic features can predict the need for eventual intervention and guide patient selection for early TEVAR. Further evidence is needed before firm conclusions could be drawn.

Cite this article as: Karkos CD, Hernandez-Lahoz I, Asaloumidis N, Papazoglou KO. The impact of thoracic endovascular aortic repair on long-term survival in type $\mathrm{B}$ aortic dissection. Ann Transl Med 2017;5(24):496. doi: 10.21037/ atm.2017.10.13

\section{Acknowledgements}

None.

\section{Footnote}

Conflicts of Interest: The authors have no conflicts of interest to declare.

\section{References}

1. Erbel R, Aboyans V, Boileau C, et al. 2014 ESC Guidelines on the diagnosis and treatment of aortic diseases:

Document covering acute and chronic aortic diseases of the thoracic and abdominal aorta of the adult. The Task Force for the Diagnosis and Treatment of Aortic Diseases of the European Society of Cardiology (ESC). Eur Heart J 2014;35:2873-926.

2. Lou X, Chen EP, Duwayri YM, et al. The Impact of Thoracic Endovascular Aortic Repair on Long-Term Survival in Type B Aortic Dissection. Ann Thorac Surg 2017. [Epub ahead of print].

3. Asaloumidis N, Karkos CD, Trellopoulos G, et al. Outcome after Endovascular Repair of Subacute Type B Aortic Dissection: A Combined Series from Two Greek Centers. Ann Vasc Surg 2017;42:136-42.

4. Steuer J, Björck M, Mayer D, et al. Distinction between acute and chronic type B aortic dissection: is there a subacute phase? Eur J Vasc Endovasc Surg 2013;45:627-31.

5. VIRTUE Registry Investigators. Mid-term outcomes and aortic remodelling after thoracic endovascular repair for acute, subacute, and chronic aortic dissection: the VIRTUE Registry. Eur J Vasc Endovasc Surg 2014;48:363-71.

6. Schwartz SI, Durham C, Clouse WD, et al. Predictors of late aortic intervention in patients with medically treated type B aortic dissection. J Vasc Surg 2017. [Epub ahead of print]. 